processing, the build-up of a toxin, or most likely a combination of several factors, that finally produces the disease. Until more is known about these processes it is unlikely that effective treatments will become available, and the sporadic sensational reports of 'a cure for Alzheimer's disease' are premature. Finally, the research into Alzheimer's disease, which is paralleled by similar approaches to other mental illnesses, also demonstrates how far psychiatry has moved towards being part of modern scientific medicine, viewing such diseases as physical disorders of the brain rather than as social or psychological problems. However valuable this may be, we must not allow the emphasis on molecules to replace our concern for people, for psychiatry will always need to attend to both equally.

\title{
The assessment of parenting: some interactional considerations
}

\author{
Peter Reder, Consultant Child Psychiatrist, Charing Cross Hospital, 2 Wolverton \\ Gardens, London W6; and CLARE LUCEY, Lecturer in Forensic Child \& Adolescent \\ Psychiatry, Westminster Children's Hospital, Vincent Square, London SW1
}

Psychiatrists are frequently invited to give expert opinions to Courts about children's emotional welfare, their parents' capacity to care for them and issues of placement and access. Previous child abuse/ neglect may have been suspected or confirmed or the parents might suffer from psychiatric symptoms. Assessment may be required of parents' mental state with a guide to prognosis, but, in addition, factors in parent-child relationships will be crucial to overall assessments of parenting.

From our perspective as child psychiatrists we shall present the framework that guides our Court assessments. This framework is not intended as a checklist or rating scale of 'normal' behaviour, but it suggests a range of themes to be assessed, some of which may be more relevant than others in any particular case. It is equally applicable to fathers, mothers or other caretakers.

\section{An interactional framework}

The factors we assess can be grouped into four, interrelated clusters: the parent's relationship with the child; the parent's relationship to the role of parenting; influences from family relationships; and relationships with the external world.

\section{The parent's relationship to the child}

The most obvious area to explore is the parent's feelings towards the child and the basis for them. In addition, the degree to which the parent enacts those feelings is important, especially if they are of hostility or rejection.
Another facet is the degree of psychological merging or differentiation between the parent and child, since the child's development requires appropriate parental responses along this continuum. Thus, some merging is involved in empathy and allows the parent to show concern for, and interest in, the child's wellbeing and experiences. It also allows the parent to put him/herself in the child's place, appreciate the child's perspective on experiences and events and acknowledge how the child must have felt when subjected to abuse or family disharmony in the past.

On the other hand, persistent lack of differentiation will draw the child into parental psychopathology and inhibit the child's psychological development and acquisition of autonomy. Therefore, we assess whether the child is viewed as a person in his/her own right, with feelings, ideas, and an identity that is different from the parent. The child's needs must be recognised, differentiated from the parent's and given primacy over them. One way that the parent can demonstrate this is by anticipating the child's needs for protection in the future and endeavouring to minimise the child's exposure to potentially dangerous situations. For example, a mother may have to chose between the security of her abused child and loyalty to the abusing partner.

\section{The parent's relationship to the role of parenting}

A number of authors have described the basic needs of children that their parents must satisfy (e.g. Kelmer Pringle, 1978; Adcock \& White, 1985). These needs differ according to the child's age and include adequate antenatal care in anticipation of the baby, 
providing physical care (i.e. food, cleanliness, warmth, health and safety), opportunities to explore, learn and socialise, reinforcement of the child's selfesteem and parenting that is sufficiently continuous and consistent.

We believe it is essential also to assess the parent's relationship to the responsibilities of being a parent. We enquire about their knowledge of, attitudes to and feelings about the task of parenting. We assess how the parents view responsibility and whether they accept responsibility for their actions instead of attributing it to someone, or something, else. For example, a parent may blame social workers for causing all the present problems by removing the children into care, or accuse the child of causing the family's breakup following his/her disclosure of abuse.

Accepting responsibility enables parents to plan for their children's future protection and the children are not expected to be responsible for their own safety in the future. Because our assessments have resulted from professionals' concern for the children's welfare, it is crucial whether the parents, too, acknowledge that parenting problems have occurred and that some changes may be necessary. We include questions on whether the parents consider that any help is needed and, if so, from whom and for what.

\section{Infiuences from the family context}

Parent-child relationships are influenced by family factors, both from the past and in the present. Because caretaking experiences may unwittingly be repeated one generation on, a parent's awareness of the impact of his/her own parenting on the ability to look after children now helps inform our assessment of whether change is possible, such as through therapy.

Unresolved family conflicts may colour the meaning of the child to the parent so that an identity is attributed to the child which is not who she/he truly is but instead what the parent wants him/her to be (Reder, Duncan \& Gray, to be published). The child may be blamed for problems in the parent's life, or parents may unreasonably hope that their conflicts will be resolved through the child.

The child may become entangled in dysfunctional family relationships to the detriment of his/her own development and be especially at risk during times of escalating parental discord. It is necessary to assess whether the family members are able to use their own emotional resources to overcome relationship tensions and their history will indicate the family's sensitivity to relationship stresses and the repertoire of solutions available to them.

Individual meetings with the child should, among other things, reveal the child's attitudes to caretaking figures, what it has been like for the child living with them and those whom the child trusts.

\section{Relationships with the external world}

The parent's willingness to give primacy to the child's needs can partially be gauged by their relationship with helping professionals. For example, a hostile avoidance of workers whose task is child protection weighs against the parents being able to put aside personal feelings for the child's sake. Similarly, there may also be a history of attempts to help the family which includes repeatedly failed interventions, suggesting that change is unlikely.

The child's welfare will also be affected by the parents' sensitivities to environmental stresses and the availability of family and community support networks, together with the parents' attitudes towards, and capacity to use, them.

The final task of the assessment is to draw the information together into coherent constructions which will be condensed into a formal Court report (see Black, Wolkind \& Harris Hendriks, 1989).

\section{Acknowledgement}

Diana Cassell, Sylvia Duncan, Chris Evered, Glenda Fredman, Moira Gray, Adam Phillips, Alejhandro Reyes and Hope Samuel helped develop the ideas reported in this paper.

\section{References}

ADCock, M. \& WHITE, R. (eds) (1985) Good-Enough Parenting: A Framework for Assessment. London: British Agencies for Adoption and Fostering.

BlaCk, D., Wolkind, S. \& HarRis Hendriks, J. (1989) Child Psychiatry and the Law. London: Gaskell (The Royal College of Psychiatrists).

Kelmer Pringle, M. (1978) The needs of children. In The Maltreatment of Children (ed. S. M. Smith). Lancaster: MTP Press.

Reder, P., Duncan, S. \& Gray, M. (to be published) Beyond Blame: Child Abuse Tragedies Revisited. London: Routledge. 